Original paper

\title{
Ratio of cord blood bilirubin and albumin as predictors of neonatal hyperbilirubinaemia
}

\author{
Indra Kumar Sharma', Dinesh Kumar ${ }^{1}$, Astitva Singh', Tariq Mahmood² \\ 'Uttar Pradesh University of Medical Sciences, India \\ 2SRMS IMS, Bhojpura, Bareilly, Uttar Pradesh, India
}

\begin{abstract}
Aim of the study: To compare cord blood albumin (CBA) and cord blood bilirubin (CBB) at birth as predictors for development of neonatal hyperbilirubinaemia.

Material and methods: CBA and CBB of 388 healthy term neonates born by lower segment caesarean section (LSCS) were determined at birth and transcutaneous bilirubin (TCB) was measured every 12 hours from birth until 7 days of life or development of hyperbilirubinaemia requiring phototherapy.

Results: The cut-off value of CBB and CBA as obtained by the receiver operating characteristic (ROC) curve was $1.90 \mathrm{mg} / \mathrm{dl}$ and $3.17 \mathrm{~g} / \mathrm{dl}$ respectively. The sensitivity, specificity and positive predictive value (PPV) for CBB were $97.4 \%, 40.6 \%$ and $71.09 \%$ while for CBA they were $40.8 \%, 34.8 \%$ and $48.41 \%$. The cut-off value for CBB/CBA ratio was 0.719 as obtained by the ROC curve and was determined to have $97.4 \%$ sensitivity, $62.6 \%$ specificity and a PPV of $79.61 \%$.
\end{abstract}

Conclusions: $\mathrm{CBB} / \mathrm{CBA}$ is a better indicator compared to $\mathrm{CBA}$ and $\mathrm{CBB}$ alone for prediction of neonatal hyperbilirubinaemia.

Key words: cord blood albumin, neonatal hyperbilirubinaemia, phototherapy, sensitivity.

Address for correspondence:

Dr. Dinesh Kumar, Associate Professor, Department of Paediatrics, Uttar Pradesh University of Medical Sciences, Saifai, Etawah. U.P, India-206130, e-mail: drdineshk79@gmail.com

\section{Introduction}

The term 'jaundice' is derived from the French word jaune, meaning yellow [1]. Jaundice is yellowish discoloration of skin, sclera and mucus membranes due to elevated levels of bilirubin in blood. Neonatal jaundice is the commonest abnormal physical finding during the first week of life [2]. More than two thirds of neonates develop clinical jaundice $[2,3]$. It affects nearly $85 \%$ of term and most preterm infants [4]. It accounts for $46 \%$ of hospital admissions in children up to 2 months of age and up to $78 \%$ in the first week of life [5].

Neonatal jaundice is the most common reason for readmission of the baby in the early neonatal period [6] which causes a financial as well as socio-economic burden on families in developing and underdeveloped countries. The American Academy of Pediatrics (AAP) recommends that newborns discharged within 48 hours should have a follow-up visit after 2-3 days to detect significant jaundice and other problems [7]. This recommendation is not possible in developing countries due to limited follow-up facilities in the community. Neonatal hyperbilirubinaemia has a self-limiting course or it can be treated easily by phototherapy when detected early in the course of illness, which prevents development of its most dreaded complication, i.e. chronic bilirubin encephalopathy (kernicterus) associated with poor outcome even after treatment. So the concept of prediction of jaundice offers an attractive option to pick up babies at risk of neonatal hyperbilirubinaemia and allows application of simple bilirubin reducing measures before bilirubin levels reach a critical limit.

Cord blood bilirubin (CBB) and cord blood albumin (CBA) are important predictors for neonatal hyperbilirubinaemia. The liver is the site of synthesis of albu$\min [3,8]$. It binds to unconjugated bilirubin and helps 
in the transport which reduces the bilirubin toxicity on the tissues, thereby competing with tissues for bilirubin binding [9]. Hence it is an important determinant of neonatal hyperbilirubinaemia. Several studies have been performed to assess the ability of CBB and CBA and first-day bilirubin levels to be tools for screening of subsequent neonatal hyperbilirubinaemia $[10,11]$. The bilirubin/albumin ratio is considered a surrogate parameter for free bilirubin and an interesting additional parameter in the management of hyperbilirubinaemia. It offers the clinician a reasonable measure of bilirubin binding to albumin until the unbound bilirubin or albumin binding reserve can be measured clinically with accuracy and precision. The current AAP guidelines for managing healthy jaundiced term and near-term newborns recommend the use of the total bilirubin concentration (TBC)/albumin ratio in addition to the TBC; however, it has not been widely used by clinicians [12]. So we tried to compare CBA with $\mathrm{CBB}$ and their ratio at birth for development of neonatal hyperbilirubinaemia.

\section{Material and methods}

This observational prospective analytical study was conducted in Department of Paediatrics, Uttar Pradesh University of Medical Sciences, Saifai, Etawah after taking duly approval from by the institutional ethical committee (ethical clearance no. 25/2017) of the university between January 2018 and July 2019. Term neonates ( $\geq 37$ weeks), weighing more than $1800 \mathrm{~g}$ and born by lower segment caesarean section (LSCS) irrespective of gender, after taking informed and written consent from parents were included in the study. Preterm neonates, birth weight $<1800 \mathrm{~g}$, babies with $\mathrm{Rh}$ and $\mathrm{ABO}$ blood group incompatibility, CBB levels $>5 \mathrm{mg} / \mathrm{dl}$, babies with significant illnesses such as neonatal sepsis, birth asphyxia, respiratory distress syndrome, meconium aspiration syndrome, any who were critically ill or haemodynamically unstable and whose parents did not give consent were excluded. A total of 397 neonates were enrolled in our study, 9 of whom were excluded after application of exclusion criteria; for the remaining 388 neonates full history was taken with emphasis on antenatal and perinatal history (maternal illness, drugs, fever with rash) and relevant data were obtained from the maternal case-sheet. After delivery of the newborn the umbilical cord was double clamped and cut at the placental end. As soon as the neonate was removed from the operative field the cord blood sample was taken after clamping the cord with a sterile cord clamp at the neonatal end and puncturing the cord with a $5 \mathrm{ml}$ syringe at a suitable point after taking proper aseptic measures, during the whole procedure the umbilical cord was held in a slanting manner for ease of sample collection. Squeezing of the cord was avoided during sample collection to prevent haemolysis of blood. Around $2 \mathrm{ml}$ of cord blood sample was collected in two vacutainers - one EDTA and another plain. The collected blood sample was stored away from light to prevent degradation. The plain vacutainer was sent to the biochemistry laboratory for estimation of serum albumin and bilirubin and the EDTA vacutainer was sent to the haematology laboratory for determination of $\mathrm{ABO}-\mathrm{Rh}$ blood group. The gestational age was determined using the New Ballard Score. Since the neonates included in our study were normal stable infants they were shifted to the mother's side for regular care and early breastfeeding. In the post-natal care ward transcutaneous bilirubin measurements were done every 12 hours from birth until 7 days of life or development of hyperbilirubinaemia requiring phototherapy for management. Transcutaneous bilirubin (TCB) levels were estimated with a Jaundice Meter by placing the instrument on the baby's sternum. The sternum was taken as the principal site of measurement as several studies have shown an excellent relation with total serum bilirubin (TSB) compared to the other sites $[13,14]$. The average of three readings was taken as the TCB value. We used cut-off values provided by AAP percentile based hour specific transcutaneous nomogram according to age, for starting phototherapy on the basis of values of TCB [6]. The baby was then shifted to NICU for phototherapy. Blood samples were collected under proper aseptic precautions and sent for estimation of serum bilirubin and sepsis screen. Phototherapy was started after covering eyes, genitals and applying a skin tag. During the phototherapy hydration and temperature were assessed by an on-duty doctor and the baby was removed from phototherapy only for feeding. Measurement of TCB was done every 12 hourly for approximate estimation of bilirubin. Phototherapy was stopped when two consecutive readings 12 hours apart fell within the hour specific nomogram. Simultaneously serum bilirubin from venous blood was sent for investigation and the baby was shifted to the mother's side for further care. The data were entered in an MS EXCEL spreadsheet and analysis was done using SPSS version 22.0.

\section{Observations}

Out of 388 newborns 181 (46.65\%) were female and the rest 207 (53.35\%) were male. The average birth weight of the newborns in our study was $2.86 \pm 0.47 \mathrm{~kg}$ with a minimum weight of $1.8 \mathrm{~kg}$ and maximum weight of $4.25 \mathrm{~kg}$. Other parameters which were ob- 
served are given in Table 1. The neonates developing pathological hyperbilirubinaemia were treated by phototherapy as per protocols and none of the babies required exchange transfusion.

Table 1. Demographic and other characteristics

\begin{tabular}{|c|c|}
\hline Parameters & \\
\hline Female, $n(\%)$ & $181(46.65 \%)$ \\
\hline Male, $n(\%)$ & $207(53.35 \%)$ \\
\hline Birth weight in $\mathrm{kg}$ (mean $\pm \mathrm{SD}$ ) & $2.86 \pm 0.47$ \\
\hline Gestational age in weeks (mean \pm SD) & $38.44 \pm 1.47$ \\
\hline Cord blood bilirubin at birth (mg/dl) (mean \pm SD) & $2.50 \pm 0.91$ \\
\hline Cord blood albumin at birth (gm/dl) (mean \pm SD) & $3.23 \pm 0.64$ \\
\hline $\begin{array}{l}\text { Cord blood bilirubin to albumin ratio at birth } \\
\text { (mean } \pm S D \text { ) }\end{array}$ & $0.84 \pm 0.51$ \\
\hline TCB at birth $(\mathrm{mg} / \mathrm{dl})($ mean $\pm \mathrm{SD})$ & $0.74 \pm 0.50$ \\
\hline TCB at day $3(\mathrm{mg} / \mathrm{dl})($ mean $\pm \mathrm{SD})$ & $8.59 \pm 3.23$ \\
\hline TCB at day $7(\mathrm{mg} / \mathrm{dl})($ mean $\pm \mathrm{SD})$ & $8.50 \pm 2.44$ \\
\hline Peak TCB (mg/dl) (mean \pm SD) & $12.34 \pm 3.21$ \\
\hline Average life in hours for peak TCB & 111.66 \\
\hline $\begin{array}{l}\text { Newborns developing pathological } \\
\text { hyperbilirubinaemia, } n(\%)\end{array}$ & $77(19.84 \%)$ \\
\hline Average life in hours for start of phototherapy & 83.68 \\
\hline Average TCB for start of phototherapy (mg/dl) & 16.32 \\
\hline
\end{tabular}

$T C B$ - transcutaneous bilirubin
Out of a total of 388 neonates 77 (19.84\%) developed hyperbilirubinaemia. We divided the population into 2 groups on the basis of levels of cord blood bilirubin taking a cut-off of $2.3 \mathrm{mg} / \mathrm{dl}$ (as found in other studies) [15]. Out of the total 388 newborns, 194 had cord blood bilirubin levels less than $2.3 \mathrm{mg} / \mathrm{dl}$ and the remaining 194 newborns had greater than or equal to $2.3 \mathrm{mg} / \mathrm{dl}$. Out of the 77 newborns developing pathological hyperbilirubinaemia, 2 (2.6\%) had a cord blood bilirubin level less than $2.3 \mathrm{mg} / \mathrm{dl}$ while the remaining $75(97.4 \%)$ had a level greater than or equal to $2.3 \mathrm{mg} / \mathrm{dl}$. Out of 311 newborns not having pathological hyperbilirubinaemia $192(61.74 \%)$ had a cord blood bilirubin level less than $2.3 \mathrm{mg} / \mathrm{dl}$ while the remaining $119(38.26 \%)$ had a cord blood bilirubin level greater than or equal to $2.3 \mathrm{mg} / \mathrm{dl}$.

We further classified neonates into 3 groups on the basis of cord blood albumin. These groups were CBA less than $2.9 \mathrm{~g} / \mathrm{dl}, 2.9$ to $3.29 \mathrm{~g} / \mathrm{dl}$ and more than or equal to $3.3 \mathrm{~g} / \mathrm{dl}$ [3]. Of the total 388 newborns, $101(26.03 \%)$ had cord blood albumin less than $2.9 \mathrm{~g} / \mathrm{dl}$ while $87(22.42 \%)$ had levels between 2.9 and $3.29 \mathrm{~g} / \mathrm{dl}$ while 200 (51.54\%) had CBA levels more than $3.3 \mathrm{~g} / \mathrm{dl}$. In the 77 newborns developing pathological hyperbilirubinaemia 33 (42.85\%) had CBA values less than $2.9 \mathrm{~g} / \mathrm{dl}$, 21 (27.27\%) had CBA between 2.9 and $3.29 \mathrm{~g} / \mathrm{dl}$ while $22(29.87 \%)$ had CBA more than $3.3 \mathrm{~g} / \mathrm{dl}$ (Table 2).

Table 2. Incidence of pathological hyperbilirubinaemia in relation to CBB levels and CBA levels

\begin{tabular}{lccccc}
\hline & \multicolumn{2}{c}{ Cord blood bilirubin (CBB) } & \multicolumn{3}{c}{ Cord blood albumin (CBA) } \\
\cline { 2 - 6 } & $<2.3 \mathrm{mg} / \mathrm{dl}$ & $\geqslant 2.3 \mathrm{mg} / \mathrm{dl}$ & $<\mathbf{2 . 9} \mathbf{~ g / d l}$ & $\mathbf{2 . 9 - 3 . 2 9} \mathrm{g} / \mathrm{dl}$ & $\geqslant 3.3 \mathrm{~g} / \mathrm{dl}$ \\
\hline TCB falling in pathological range & $2(2.6 \%)$ & $75(97.4 \%)$ & $33(42.9 \%)$ & $20(26 \%)$ & $24(31.2 \%)$ \\
\hline TCB not falling in pathological range & $192(61.7 \%)$ & $119(38.3 \%)$ & $68(21.7 \%)$ & $67(21.5 \%)$ & $176(56.6 \%)$ \\
\hline Total & 194 & 194 & 101 & 87 & 200 \\
\hline
\end{tabular}

$T C B$ - transcutaneous bilirubin

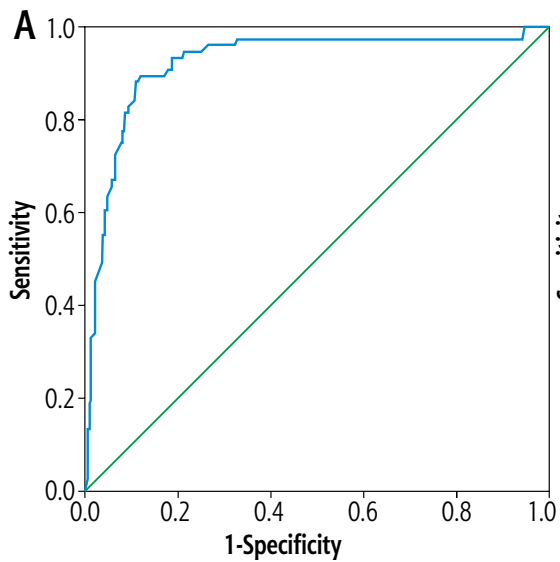

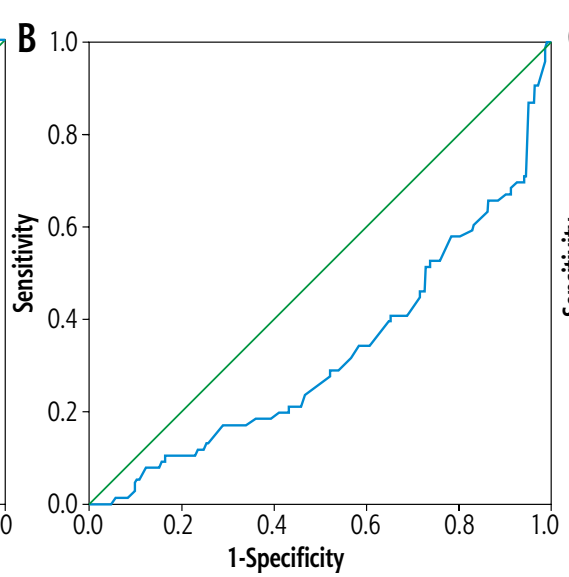

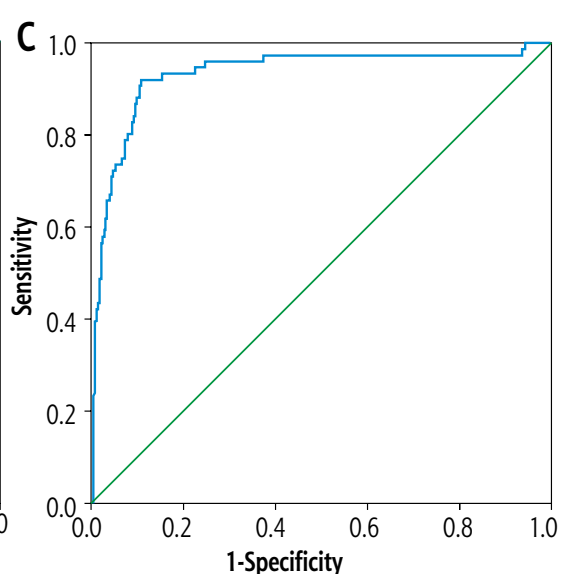

Fig. 1. ROC curve denoting sensitivity and specificity for A) cord blood bilirubin (CBB), B) cord blood albumin (CBA), and C) CBB/CBA ratio for the prediction of development of pathological hyperbilirubinaemia

Diagonal segments are produced by ties. 
Table 3. Sensitivity and specificity of $\mathrm{CBB}, \mathrm{CBA}$ and $\mathrm{CBB} / \mathrm{CBA}$ ratio in detecting pathological hyperbilirubinaemia

\begin{tabular}{|c|c|c|c|c|c|c|}
\hline \multirow{2}{*}{\multicolumn{2}{|c|}{ Area under curve }} & \multicolumn{2}{|c|}{$95 \%$ confidence interval } & \multirow[t]{2}{*}{ Cut-off value } & \multirow{2}{*}{$\begin{array}{c}\text { Sensitivity } \\
\text { (\%) }\end{array}$} & \multirow{2}{*}{$\begin{array}{c}\text { Specificity } \\
(\%)\end{array}$} \\
\hline & & Lower bound & Upper bound & & & \\
\hline CBB & 0.923 & 0.885 & 0.962 & $1.90 \mathrm{mg} / \mathrm{dl}$ & 97.4 & 40.6 \\
\hline CBA & 0.327 & 0.257 & 0.397 & $3.17 \mathrm{gm} / \mathrm{dl}$ & 40.8 & 34.8 \\
\hline $\begin{array}{l}\mathrm{CBB} / \mathrm{CBA} \\
\text { ratio }\end{array}$ & 0.932 & 0.895 & 0.970 & 0.719 & 97.4 & 62.6 \\
\hline
\end{tabular}

CBB - cord blood bilirubin, CBA - cord blood albumin

Figure 1 and Table 3 show that a cut-off value of cord blood bilirubin was $1.90 \mathrm{mg} / \mathrm{dl}$ as obtained by the ROC curve determined to have $97.4 \%$ sensitivity, $40.6 \%$ specificity and a positive predictive value (PPV) of $71.09 \%$ with a standard error of 0.020 under the non-parametric assumption. The cut-off value of cord blood albumin was $3.17 \mathrm{~g} / \mathrm{dl}$ obtained by the ROC curve and was determined to have $40.8 \%$ sensitivity, $34.8 \%$ specificity and a PPV of $48.41 \%$ with a standard error of 0.036 under the non-parametric assumption. The cutoff value for cord blood bilirubin to albumin ratio was 0.719 as obtained by the ROC curve, determined to have $97.4 \%$ sensitivity, $62.6 \%$ specificity and a PPV of $79.61 \%$ with a standard error of 0.019 under the non-parametric assumption.

\section{Discussion}

In resource constrained countries where the patient to bed ratio is very high, early prediction of hyperbilirubinaemia will help in early discharge, prevent re-hospitalization and reduce duration of hospital stay of babies and mothers $[16,17]$. So there is a constant need for a marker which can be reliably used to predict development of significant jaundice in a neonate. In our study we observed $19.84 \%$ incidence of neonatal jaundice, which is similar to Bernaldo et al. [18], who reported a more or less similar incidence of $19.86 \%$. Some similar studies report a lower incidence of $10.7 \%$ [19], 12.80\% [20], 10.30\% [21], 10.60\% [22] and 9.5\% [23] though some studies report a high incidence rate varying from $34 \%$ up to $54.3 \%[24,25]$. These differences may be due to different racial and ethnic groups or various inclusion or exclusion criteria considered in various studies. With the receiver operating characteristic (ROC) curve analysis the cut-off CBB level $(1.90 \mathrm{mg} / \mathrm{dl})$ in our study was lower than that of previous such studies by Knudsen et al. [15], Taskande et al. [23], Sun et al. [26] and Ahire et al. [27], which reported a cut-off of $2.3 \mathrm{mg} / \mathrm{dl}, 2.0 \mathrm{mg} / \mathrm{dl}$, $2.0 \mathrm{mg} / \mathrm{dl}$ and $3.0 \mathrm{mg} / \mathrm{dl}$ respectively, which can be explained by detection of neonatal jaundice at the early stage due to application of transcutaneous bilirubinometry. The cut-off value for CBA by ROC curve analy- sis was $3.17 \mathrm{~g} / \mathrm{dl}$ while the values in previous studies were $2.6 \mathrm{~g} / \mathrm{dl}$ [10], $3.0 \mathrm{~g} / \mathrm{dl}$ [11], $2.75 \mathrm{~g} / \mathrm{dl}$ [25], $2.75 \mathrm{~g} / \mathrm{dl}$ [28] and $2.95 \mathrm{~g} / \mathrm{dl}$ [29]. The difference observed may be due to the small sample size and inclusion of sick and premature neonates in these studies. In order to obtain a higher sensitivity and specificity than either $\mathrm{CBB}$ or CBA alone we decided to use them in combination as the $\mathrm{CBB}$ to $\mathrm{CBA}$ ratio. The ROC curve analysis on the $\mathrm{CBB} / \mathrm{CBA}$ ratio revealed a cut-off point of 0.719 with sensitivity of $97.4 \%$, specificity of $62.6 \%$, PPV of $79.61 \%$ and negative predictive value (NPV) of $94.13 \%$ while the cut-off point for $\mathrm{CBB} / \mathrm{CBA}$ ratio obtained in other studies for prediction of development of significant hyperbilirubinaemia was 0.6 [11], 0.78 [28], 0.98 [30]. This variation in cut-off value may be due to the difference in sample size and estimation methods of bilirubin in other studies. The area under the curve of $\mathrm{CBB} / \mathrm{CBA}$ ratio by ROC curve analysis is 0.932 , which is also higher than that of CBB and CBA considered alone. On the basis of the above discussion it can be inferred that $\mathrm{CBB} / \mathrm{CBA}$ ratio is a better predictor for development of neonatal hyperbilirubinaemia with high sensitivity, NPV, PPV and specificity when compared with CBB and CBA alone. Strengths of our study were unbiased enrolment, large sample size, and use of transcutaneous bilirubinometry for jaundice screening, which gave us a more uniform approach and removed observer's bias, minimally invasive procedures and above all combined the approach of CBB and CBA in the form of a ratio which provided us a new parameter which is more sensitive and specific than CBB or CBA alone.

Disadvantages of our study were that we only included babies born through the LSCS route, not including preterm and very low birth weight babies and use of transcutaneous bilirubinometry for assessment of hyperbilirubinaemia, which tends to overestimate bilirubin, although the problem is minimized to an extent as bilirubinometers are more reliable in term newborns.

\section{Disclosure}

The authors declare no conflict of interest. 


\section{References}

1. Surendran R, Vijayraghvan P. Approach to a patient with jaundice. In: Textbook of surgical gastroenterology. Mishra PK. Vol. 2. Jaypee Brothers, New Delhi 2016; 757.

2. Singh M. Jaundice. In: Care of the newborn. $8^{\text {th }}$ ed. CBS Publishers, New Delhi 2015; 324-349.

3. Sahu S, Abraham R, John J, et al. Cord blood albumin as a predictor of neonatal jaundice. Int J Bio Med Res 2011; 1: 436-438.

4. Gregory MLP, Martin CR, Cloherty JP. Neonatal hyperbilirubinemia. In: Manual of neonatal care. $7^{\text {th }}$ ed. Cloherty J, Eichenwald E, Stark A. Lippincot Williams and Wilkins, a Wolters Kluwer business, New Delhi 2012; 304-339.

5. Narang A, Kumar P, Kumar R. Neonatal jaundice in very low birth weight babies. Indian J Pediatr 2001; 68: 307-309.

6. American Academy of Pediatrics. Practice parameter: Management of hyperbilirubinemia in the healthy team newborn. Pediatrics 1994; 94: 558-567.

7. American Academy of Pediatrics. Committee on Fetus and Newborn. Hospital stay for healthy term newborns. Pediatrics 2010; 125: 405-409.

8. Trivedi DJ, Markande DM, Vidya BU, et al. Cord serum bilirubin and albumin in neonatal hyperbilirubinemia. Int J Int Sci Inn Tech 2013; 2: 39-42.

9. Bunt JE, Rietveld T, Schierbeek H, et al. Albumin synthesis in preterm infants on the first day of life studied with [1-13C] leucine. Am J Physiol Gastrointest Liver Physiol 2007; 292: 1157-1161.

10. Rajpurohit N, Kumar S, Sharma D, et al. To assess predictive value of cord blood bilirubin and albumin for significant neonatal hyperbilirubinemia: a prospective study from India. J Pediatr Neonatal Care 2015; 2: 00060.

11. Khairy MA, Abuelhamd WA, Elhawary IM, et al. Early predictors of neonatal hyperbilirubinemia in full term newborn. Pediatr Neonatol 2019; 60: 285-290.

12. American Academy of Pediatrics Subcommittee on Hyperbilirubinemia. Management of hyperbilirubinemia in the newborn infant 35 or more weeks of gestation. Pediatrics 2004; 114: 297-316.

13. Nagar G, Vandermeer B, Campbell S, et al. Reliability of transcutaneous bilirubin devices in preterm infants: A systematic review. Pediatrics 2013; 132: 871-881.

14. Kurokawa D, Nakamura H, Yokota T, et al. Screening for hyperbilirubinemia in Japanese very low birthweight infants using transcutaneous bilirubinometry. J Pediatr 2016; 168: 77-81.

15. Knudsen A. Prediction of the development of neonatal jaundice by increased umbilical cord blood bilirubin. Acta Paediatr Scand 1989; 78: 217-221.

16. Patterson PK. A comparison of postpartum early and traditional discharge groups. QRB Qual Rev Bull 1987; 13: 365-371.

17. Waldenstrom U, Sundelin C, Lindmark G. Early and late discharge after hospital birth: Health of mother and infant in the postpartum period. Ups J Med Sci 1987; 92: 301-314.

18. Bernaldo AJ, Segre CA. Bilirubin dosage in cord blood: could it predict neonatal hyperbilirubinemia? Sao Paulo Med J 2004; 122: 99-103.

19. Palmer DC, Drew JH. Jaundice a 10 year review of 41000 live born infants. Aust Paediatr J 1983; 19: 86-89.

20. Awasthi S, Rehman H. Early prediction of neonatal hyperbilirubinemia. Indian J Pediatr 1998; 65: 131-139.

21. Agarwal R, Deorari AK. Unconjucated hyperbilirubinemia in newborn. Indian Pediatr 2002; 39: 30-42.

22. Knupfer M, Pulzer F, Gebauer C, et al. Predictive value of umbilical cord blood bilirubin for postnatal hyperbilirubinaemia. Acta Paediatr 2005; 94: 581-587.
23. Taksande A, Vilhekar K, Jain M, et al. Prediction of the development of neonatal hyperbilirubinemia by increased umbilical cord blood bilirubin. IndMedica 2005; 9: 5-9.

24. Zeitoun AA, Elhagrasy HF, Abdelsatar DM. Predictive value of umbilical cord blood bilirubin in neonatal hyperbilirubinemia. Egyptian Pediatric Association Gazette 2013; 61: 23-30.

25. Alalfy M, El Lithy A, EzzEldin ZM, et al. Role of bilirubin and albumin in cord blood as predictors for neonatal hyperbilirubinemia. J Gynecol Res 2018; 4: 208.

26. Sun G, Wang YL, Liang JF, Du LZ. Predictive value of umbilical cord blood bilirubin level for subsequent neonatal jaundice. Zhonghua Er Ke Za Chi 2007; 45: 848-852.

27. Ahire N, Sonawane R, Gaikwad R, et al. Study of correlation of cord blood bilirubin with neonatal hyperbilirubinemia. MVP J Med Sci 2016; 3: 60-66.

28. El Mashad GM, El Sayed HM, El Shafie WA. Cord blood albumin-bilirubin as a predictor for neonatal hyperbilirubinemia. Menoufia Med J 2019; 32: 1071-1077.

29. Shekhar M, Kumar V, Bhalke S, et al. Umbilical cord albumin and serum bilirubin as predictive factors for hyperbilirubinemia in term neonates. Int J Contemp Pediatr 2020; 7: 267-272.

30. Bhat JA, Sheikh SA, Ara R. Cord blood bilirubin, albumin, and bilirubin/albumin ratio for predicting subsequent neonatal hyperbilirubinemia. Paediatrica Indonesiana 2019; 59: 244-251. 